ISSN: 2238-8052

Volume 8, Número 2 (2019)

https://periodicos.ufpe.br/revistas/revistamseu

\title{
A ASSESSORIA JURÍDICA POPULAR DA UFMG: HISTÓRICO E PERSPECTIVAS FUTURAS
}

\author{
EL POPULAR ASESORAMIENTO LEGAL DE LA UFMG: \\ RESCATE HISTÓRICO Y PERSPECTIVAS FUTURAS
}

\author{
João Pedro Esteves de OLIVEIRA ${ }^{1}$ \\ Luciana Grossi Araújo de CASTRO ${ }^{2}$ \\ Helena Carvalho COELHO ${ }^{3}$ \\ Taynara Gabriele Inácio OLIVEIRA ${ }^{4}$
}

Artigo recebido em 30/04/2019 e aceito em 04/07/2019

Palavras-chave: Assessoria Jurídica Popular da UFMG, Extensão Universitária, Origem, Protagonismo estudantil.

Keywords: Asesoría Jurídica Popular da UFMG, Extensión universitaria Origen, Protagonismo del movimiento estudiantil.

\section{R E S U M O}

Tendo em vista a importância de um permanente resgaste histórico de assessorias jurídicas e da construção coletiva de um projeto, este artigo teve como objetivo dar continuidade a trabalhos anteriores e trazer o presente da história da Assessoria Jurídica Popular (AJUP) da UFMG. Objetivou-se aqui registrar como foram solucionados os desafios particulares e os comuns às assessorias jurídicas universitárias, tais como o estabelecimento do protagonismo estudantil e a criação de diálogo entre extensionistas e comunidades. Foram realizadas entrevistas à ex-membros da AJUP, utilizando a metodologia bola de neve (snow ball), utilizando os relato dos entrevistados para a descrição do surgimento, dos participantes e dos desafios e conquistas encontradas e pela assessoria.

\section{A B S T R A C T}

Dada la importancia de una revisión histórica permanente del asesoramiento legal y la construcción colectiva de un proyecto, este artículo tuvo como objetivo continuar el trabajo previo y presentar el presente de la historia de la Asesoría Jurídica del Pueblo (AJUP) de UFMG. El objetivo aquí es registrar cómo se resolvieron los desafíos particulares y comunes para los asesores legales universitarios, como el establecimiento del liderazgo estudiantil y la creación de diálogo entre los extensionistas y las comunidades. Las entrevistas se realizaron con ex miembros de AJUP, utilizando la metodología de bola de nieve, utilizando los informes de los entrevistados para describir el surgimiento, los participantes y los desafíos y logros encontrados y por el asesoramiento.

\footnotetext{
1 Graduando em Direito na Universidade Federal de Minas Gerais - UFMG. Extensionista da AJUP-UFMG. E-mail: joaopesteves1@gmail.com.

2 Graduada em Direito na Universidade Federal de Minas Gerais - UFMG. Extensionista da AJUP-UFMG. E-mail: lucianagac2@gmail.com.

3 Doutoranda em Direito na Universidade Federal de Minas Gerais - UFMG. Co-coordenadora da AJUP-UFMG. E-mail: helenacarvalho9@gmail.com.

4 Graduanda em Direito na Universidade Federal de Minas Gerais - UFMG. Ex-extensionista daAJUP-UFMG E-mail: taynaraginacio@outlook.com.
} 


\section{INTRODUÇÃO}

O presente trabalho visa contribuir para um resgate histórico da Assessoria Jurídica Popular da Universidade Federal de Minas Gerais (AJUP-UFMG). Mais além, visa registrar como foram solucionados dentro da experiência da AJUP/UFMG os desafios comuns às assessorias jurídicas universitárias. As dificuldades de se estabelecer o protagonismo estudantil e um diálogo próximo entre os extensionistas e as comunidade assessoradas serão, portanto, temas recorrentes neste trabalho. Contudo, não se fazem menores os desafios criados pela judicialização - ou não - das demandas populares. A análise dos casos, os caminhos a serem percorridos e as dificuldades decorrentes da judicialização são também presentes na experiência da extensão. Nesse sentido, pensando desde dentro pelos extensionistas que estão atualmente na AJUP, realizamos entrevistas semiestruturadas com ex-membros da AJUP. Utilizando a metodologia bola de neve, além de revisão teórica dos trabalhos produzidos sobre as assessorias jurídicas populares e, especificamente, sobre a AJUP da UFMG.

A metodologia bola de neve (snow ball) consiste em "[...] encontrar um caso pertencente a um grupo objeto de pesquisa e este levará ao seguinte e ao próximo e assim sucessivamente até alcançar o nível de informação suficiente para dar por terminada a pesquisa." ${ }^{5}$ (QUINTANA, 2006, p. 58), o que na prática significa que os participantes escolherão o próximo Entrevistado - com uma menor margem de ingerência possível do entrevistador, uma vez que o entrevistador não controla o fluxo de pessoas e terminará as entrevistas somente quando não houver mais nada novo no conteúdo apresentado suficiência das informações. Por isso, a metodologia bola de neve tem viés qualitativo, visto que considera a qualidade das informações, não sendo tão fundamental o número de entrevistas. Para a elaboração do trabalho foram entrevistados sete (07) extensionistas, compreendendo extensionistas que participaram desde a primeira formação em 2013 até o primeiro semestre de 2018. Os autores preferiram identificar os Entrevistados pela sequência em que foram ocorrendo às entrevistas ficando da seguinte forma: Entrevistado 1, Entrevistada 2, Entrevistada 3, Entrevistada 4, Entrevistada 5, Entrevistado 6 e Entrevistada 7.

Considerando a atual conjuntura política, econômica e social, levantar o histórico da AJUP é entender os horizontes possíveis, as dificuldades passadas e presentes e os desafios que permeiam as atividades de uma assessoria jurídica popular e da extensão universitária. Extensão essa pautada pela pedagogia freireana de proporcionar o nascimento da autonomia em todos os sujeitos envolvidos (FREIRE, 2002) e pela crítica marxista ao direito, que será melhor apresentada ao fim desse trabalho.

5Tradução livre do trecho "[...] encontrar un caso perteneciente al grupo objeto de investigación y éste lleva al siguiente y al próxima y así sucesivamente hasta alcanzar el nivel de información suficiente para dar por terminada la investigación" QUINTANA, A. y Montgomery, W. (org.). Psicología: Tópicos de actualidad. Lima: UNMSM, 2006. p. 58. 
O que, sem dúvidas, além de apontar horizontes possíveis à extensão, também trata-se de reconhecer os limites da atuação jurídica.

\section{A ASSESSORIA JURÍDICA POPULAR DA UNIVERSIDADE FEDERAL DE MINAS GERAIS (AJUP- UFMG): DE ONDE VIEMOS?}

A Assessoria Jurídica Popular da UFMG surge em 2012/2013 em um contexto de possibilidades e lutas construídas durante a primeira década dos anos 2000, muito inspirados nas demais assessorias jurídicas populares já existentes no Brasil e no histórico de resistência da ditadura militar, em que os advogados tiveram papel muito importante no pós-golpe. Os anos 2000 foram muito frutíferos para a consolidação de movimentos sociais, assessorias jurídicas e, até mesmo, organizações não governamentais. Foi um momento de efervescência de lutas, em que o Fórum Social Mundial, em 2005, permitiu pensar a América Latina e semeou os horizontes possíveis para novas formas de luta. Muito amparadas na educação popular como máxima, tendo como uma das grandes referências o Paulo Freire, e com a crítica ao direito, as assessorias jurídicas populares propunham-se, assim como outros projetos de extensão surgidos no período de redemocratização, um novo modelo de universidade pautado desde baixo, com a inclusão de minorias, tanto no diálogo na universidade, quanto ocupando vagas nos cursos.

Historicamente, as Assessorias Jurídicas Populares surgiram no contexto estudantil, nas décadas de 1950 e 1960, e foram criadas, inicialmente, com o intuito de estimular a prática jurídica no meio universitário e de aproximação da universidade com setores populares. Essas diretrizes acabaram por fazer aflorar nas AJUP existentes - SAJU da UFRGS e SAJU da UFBA, forte politização. Essa mesma politização fez com que, durante a ditadura civil-militar, as assessorias jurídicas universitárias fossem desarticuladas, como parte das ofensivas do regime às movimentações estudantis do período (ALMEIDA, 2015, p. 70).

Com o processo de redemocratização, as AJUP puderam se organizar de maneira mais sólida, ampliando a restrita atividade de resistência que exerciam durante o regime. Elas então se juntaram a todos aqueles novos movimentos de esquerda que emergiram na época e que visavam, de uma maneira ou outra, questionar a ordem do capital. A conformação dos novos movimentos de esquerda com as estruturas tradicionais já existentes permitiram a organização das redes de advocacia popular e assistência jurídica universitária que se articularam, assim, com sindicatos e outros movimentos sociais já consolidados.

A Assessoria Jurídica da Universidade Federal de Minas Gerais tem uma construção recente, em um contexto específico e muito diferente do contexto de surgimento das AJUP no Brasil. Não temos como objetivo aqui construir um histórico desses grupos de assessoria, mas sim entender de onde a 
AJUP/UFMG veio, quais as bases que foram construídas para esse surgimento e quais as particularidades dessa AJUP. Para tanto, analisamos os relatos dos ex-ajupianos entrevistados, em que a partir deles é possível inferir que Assessoria Jurídica da UFMG é um movimento construído em decorrência do protagonismo universitário e do desejo em romper com os muros da universidade, permitindo um trabalho conjunto e um retorno à sociedade.

Foi unânime nas entrevistas que a AJUP surgiu em decorrência do movimento estudantil e dos encontros nacionais e regionais dos estudantes de direito nos quais integrantes do Centro Acadêmico Afonso Pena (CAAP) tiveram contatos com AJUP de outros estados. 0 contato com o projeto de assessoria jurídica popular mobilizou os estudantes de Direito da UFMG para a construção da Assessoria Jurídica Popular.

Foi em 2012 que a iniciou-se, assim, reflexão a respeito dos trabalhos que seriam desenvolvidos, do papel dos estudantes no processo de assessoria e da função da Universidade. Além disso, foi consenso entre os Entrevistados 1, 2 e 3 a atuação ativa do Centro Acadêmico Afonso Pena (CAAP) que, após encontros nacionais e regionais de estudantes de Direito, organizou um seminário sobre as assessorias jurídicas universitárias, com leitura de textos de Paulo Freire e com a problematização do papel da universidade. Houve ainda a reflexão sobre a assessoria jurídica popular e sobre os pontos de atuação na cidade de Belo Horizonte. O seminário atraiu estudantes para além daqueles envolvidos com CAAP e teve como resultado a constituição da primeira geração de ajupianos.

O movimento de institucionalização e inserção ocorreu em 2013, com o projeto de AJUP já articulado pelos estudantes. A Entrevistada 2 mostrou que a formalização da Assessoria enquanto projeto de extensão teve grande empenho dos alunos, pois ao passo que trabalhavam com os documentos para a formalização, atuavam no campo colocando em prática a forma de agir da AJUP. 0 Entrevistado 1 trouxe memórias ricas em ao lembrar que a horizontalidade e o protagonismo estudantil foram eixos presentes desde a fundação e a construção da AJUP, que se deu com a reunião dos estudantes e com o uso das tecnologias do Google Drive e Google Docs na criação e discussão dos projetos e marcos teóricos.

Após o primeiro momento de construção e criação coletiva da AJUP, era necessário institucionalizá-la dentro da Universidade Federal de Minas Gerais e Faculdade de Direito e Ciências do Estado enquanto projeto. Para alcançar esse objetivo, foi preciso buscar um professor orientador que estivesse disposto a assumir a coordenação do projeto e lidar com as questões burocráticas sem interferir nos pilares do protagonismo estudantil e da horizontalidade da AJUP. Como trouxe o Entrevistado 1, os primeiros orientadores respeitaram a autonomia universitária e o protagonismo e proatividade dos estudantes, característica muito marcante e fundamental para as assessorias jurídicas populares no Brasil todo. Além disso, os alunos precisavam de auxílio administrativo para suas atividades. Nesse sentido, o respaldo institucional demonstrou ter sido a melhor opção para 
fundadores da AJUP, pois possibilitou aos estudantes terem o vínculo de extensionistas, bolsas de extensão, a adquirir de materiais para o desenvolvimento dos trabalhos - conseguidos por meio de editais de fomento à extensão - e uma sala no Edifício Villas-Bôas, na Faculdade de Direito e Ciências do Estado da UFMG. Essas aquisições foram mencionadas positivamente em todas as entrevistas, direta ou indiretamente, o que se depreende como tendo sido de grande valia na condução e desenvolvimento dos trabalhos e, principalmente, para um melhor agir dos estudantes contemplados pela bolsa de extensão.

O Entrevistado 1 lembrou que, durante os seminários e reuniões que precederam a fundação do projeto e que buscaram avaliar as possibilidades de atuação, foi delineada a perspectiva de trabalhar com o Movimento dos Trabalhadores por Direito (MTD), na época Movimento dos Trabalhadores Desempregados, na Pedreira Prado Lopes (PPL), favela mais antiga de Belo Horizonte. O Entrevistado 1 trouxe que esse foi o primeiro (e por algum tempo o único) trabalho da AJUP, que construiu as bases e se centrou na Pedreira Prado Lopes.

Entre os trabalhos desenvolvidos nessa comunidade todos os Entrevistados destacaram o processo de formação de uma associação dos moradores, análise do perfil dos moradores dos prédios ofertados pelo programa Vila Viva, ocupação de prédios antigos, atividades no centro cultural, participações judiciais, junto à Defensoria Pública, para a consolidação de serviços de saneamento básico.

Desde 2018, a AJUP-UFMG também assessora o movimento Tarifa Zero-BH, ampliando a atuação territorial baseada no solo periférico e pensando a cidade nas conexões possíveis que um movimento de mobilidade urbana permite.

\subsection{Os desafios da caminhada enquanto ajupiano}

O que é ser ajupiano? 0 que faz um estudante de graduação ser ajupiano para além de simplesmente frequentar um projeto de extensão com paradigmas distintos do que seria esperados para uma das tradicionais faculdade de direito do país? A Entrevistada 3 pontuou que, embora a AJUP seja um projeto fora dos padrões, deve ser encarado com seriedade e comprometimento, caso contrário, o estudante estaria criando mais uma dificuldade ao projeto. Isso em razão da horizontalidade que se propõe entre membros e coordenação e entre membros e movimentos sociais.

Então, como caracterizar um ajupiano? A Entrevistada 2 apontou que pela vivência dela que não existe um "perfil", mas sim habilidades que caracterizam bons ajupianos tais como ser aberto ao diverso, ouvir, escutar e entender as diferentes situações e desafios que surgem, por sua seriedade, proatividade, e pelas assessorias e as pesquisas realizadas. A Entrevistada 2 ainda ressaltou que a AJUP é um projeto de extensão com recorte político dentro do campo das esquerdas, então é essencial 
à um ajupiano a capacidade de dialogar e entender outras perspectivas políticas e discursivas. Dessa forma, é um projeto de extensão que potencializa a diversidade, ajuda a questionar o "mito" positivista das ciências sociais aplicadas neutras e ajuda no amadurecimento do estudante em perceber que as universidades públicas e federais têm um papel político e social para e junto com a comunidade e a sociedade.

As Assessorias Jurídicas Universitárias Populares, como parte de sua origem histórica, são respostas à conjuntura social, que permitem que os estudantes desenvolvam e tomem posições políticas em prol dos sujeitos trabalhadores e subalternizados na ordem do capital (ALMEIDA, 2015, p. 325). Ademais, proporcionam o início da criação de um direito emancipatório tanto para os estudantes em seu caminho pela graduação quantos para os sujeitos assessorados, trazendo para o ensino jurídico a dialética e a educação popular e emancipatória de Paulo Freire (FREIRE, 2002).

E justamente por trazerem essa forma dialética, que respeita os diferentes saberes dos diversos sujeitos, é que o modelo de Assessoria Jurídica Universitária Popular se necessário,ainda que penoso e de difícil abertura dentro da Faculdade de Direito, pois o modelo jurídico imposto exige que os estudantes atuem como detentores do saber, o que diverge diametralmente dos princípios que direcionam as AJUP. Isso porque as Assessorias Jurídicas Universitárias Populares são focadas no protagonismo e autonomia estudantis e como partindo do conceito de que as pessoas só podem aprender a autonomia a partir da interação social percebe-se que é uma necessidade humana dialógica e torna falsa a concepção de autonomia como autossuficiência e de indivíduo isolado que se satisfaz no isolamento (GUSTIN, 1999, p. 32).

Portanto, a AJUP é o tipo de projeto de extensão vanguardista, ou seja, que vai além dos paradigmas tradicionais do direito, e que permite algo que a educação jurídica tradicional não proporciona há algumas centenas de anos, com poucas variações (CAPELLA, 2011), que é vivenciar a realidade social de um país dos mais desiguais no mundo. Vale lembrar que, em 2017, a Pesquisa Nacional por Amostra de Domicílios (PNAD), apontou que os $10 \%$ mais ricos da população brasileira detinham $43 \%$ das riquezas, enquanto os $10 \%$ mais pobres detinham apenas $0,7 \%$, demonstrando claramente nossa desigualdade social (IBGE, 2018). E é o movimento de ir até movimentos sociais e ouvir suas demandas e necessidades e buscar meios de auxiliá-los na busca dessa independência e autonomia, prática que revela sua vertente freireana.

Os Entrevistados 1, 2 e 3 trazem muito da construção inicial e dos desafios envolvendo a reflexão e concepção do que é assessoria jurídica popular e como institucionaliza-la sem perder o protagonismo dos estudantes e da horizontalidade característicos de uma AJUP. Adentrando na institucionalização, foi necessário aos fundadores se afastarem do centro acadêmico, o CAAP, pois este demonstrou que não daria o suporte necessário a extensão. Por isso, buscaram a aprovação e o suporte da Universidade Federal de Minas Gerais em reconhecer a AJUP como projeto de extensão e 
proporcionar equipamentos para facilitar a assessoria, por exemplo, a sala e as bolsas de extensão. Houve o cuidado dos fundadores em, ao institucionalizar como extensão, não burocratizar demais a ponto de criar entraves aos projetos e aos marcos teóricos que fundamentam uma AJUP.

Outro elemento que apareceu em todas as entrevistas foi o das controversas na figura do professor coordenador, que é o responsável administrativamente pela extensão, pois se em alguns momentos um dos orientadores era ausente ou não orientava em outros momentos outros orientadores não compreenderam a estrutura de uma AJUP e solaparam a autonomia e o protagonismo estudantil. Os desafios em buscar um(a) professor(a) orientador(a) que simultaneamente orientasse quando necessário e respeitasse os pilares da AJUP - autonomia, horizontalidade nas relações e no protagonismo dos estudantes - foi e é uma constante nas diversas gerações de ajupianos. 0 relato de uma das entrevistadas ilustra bem o que se deseja de um orientador próximo dos estudantes:

[...] Nesse aspecto, o papel dos estudantes e dos orientadores precisam alinhar-se em uma construção conjunta, que tenha em mente a autonomia dos estudantes e a construção de uma horizontalidade como meta, tratando essa expressão com a seriedade de construção de um processo contínuo. Assim, por parte desses, em orientar principalmente nas questões jurídicas e institucionais, respeitando o trabalho e o papel dos extensionistas e por parte daqueles, em uma abertura aos professores, para possibilitar uma construção coerente.[...]

Entrevistada 2

Ainda na parte do desenvolvimento-consolidação, focados principalmente nos trabalhos de campo realizados na Pedreira Prado Lopes (PPL), os desafios se relacionam com os moradores, o movimento social e o desenvolvimento dos trabalhos em grupo. Sobre os moradores, o desafio dos estudantes foi em romper os muros da universidade e ir até os sujeitos assistidos e tentar ouvir, entender e assistir em suas demandas, ou como outra expressão traz muito bem "romper as torres de marfim" da universidade. Os Entrevistados 1 e 2 apontaram a dificuldade desse processo por serem muito jovens e inexperientes tanto no curso quanto na vida, mas que o embasamento teórico em Paulo Freire e na teoria marxista junto com a vivência e experiência que foram ganhando na Pedreira Prado Lopes permitiu que, com o tempo, pudessem auxiliar no empoderamento dos moradores.

A ruptura dos muros da universidade, ou seja, aproximar o saber popular do saber acadêmico e vice-versa é um desafio constante, inclusive da conjuntura atual das universidades federais e, consequentemente, da AJUP.e levar a sociedade para dentro da universidade assim como os universitários para fora, para a realidade da maior parte da sociedade, é uma tarefa em aberto. 71\% dos Entrevistados ressaltaram a importância de se trazer os processos sociais para dentro da universidade e de reconheceram que um problema recorrente às atividades de extensão é a saída dos antigos extensionistas sem a devida transição e apresentação dos novos membros para a comunidade, o que pode gerar um afastamento da comunidade com o projeto com o passar dos anos. 
Compreender a autonomia do grupo de extensão AJUP frente às organizações populares que assessora foi e é uma tarefa constante tanto dos antigos membros, da construção inicial ao desenvolvimento-consolidação, aos membros atuais, que tiram dessa experiência a importância do diálogo e de conseguir fazer um processo que não seja voltado a algo estritamente tecnicista, e sim de proporcionar um conhecimento conjunto das partes (FREIRE, 2002), a fim de que a autonomia dos estudantes seja preservada, de que o papel da assessoria não seja confundido com assistência, de que o movimento social não seja anulado pela atuação dos extensionistas nem a extensão seja anulada pelo movimento social. Inclusive, foi trazido pelos Entrevistados 5, 6 e 7 como é importante uma extensão dentro da presente conjuntura ao invés das práticas de Empresas Jrs., ou a prática do empreendedorismo, metodologia de extensão adotada com maior frequência nos últimos três anos na UFMG.

[...] se a gente fala da nossa conjuntura, a gente vê muito a inserção de empresas júnior no contexto das universidades, né. $\mathrm{E}$ a gente sabe, né, quando a gente fala de empresa júnior, por mais que tenha um caráter, sei lá, de ajudar as comunidades, a gente sabe o que tem por trás disso, que são empresas lucrando.. e, também um problema que a gente tem com extensão [...] é a questão da atuação, né, você pega o que é produzido dentro das universidades e leva esse conhecimento pras comunidades, mas claro que tem suas limitações, né. Mas, pras comunidades ao redor, né, e aí a importância de a AJUP ser um projeto de extensão popular, é.... dentro dessa conjuntura eu vejo que é muito essa questão de resistência, né, tanto no corte de bolsas, quanto com o fortalecimento das empresas júniors.. (...) Então é.. eu acho que vai mais nesse sentido, de resistência a esses retrocessos dentro das universidades e até fora, em certa medida, de levar o que a gente aprende aqui dentro, com limitações, como qualquer tipo de coisa dentro do capital, mas ajuda, é importante.[...]

Entrevistada 5

Como observado no trecho da entrevista, a metodologia das Empresas Jrs., ainda que voltadas para intenção da justiça social, impõem a prática do capital em quem já é subalternizado, ou seja, em quem já é expropriado de todas as maneiras pelo sistema. Ademais, observa-se que a metodologia na qual a AJUP se apoia - ensino popular, horizontalidade e protagonismo estudantil - permite maior aprendizado dos estudantes, pois estes são predominantes do início do curso, e intercâmbio de conhecimento com a comunidade, algo que não ocorre com outras práticas.

0 desafio maior e mais constante no dia-dia e nas gerações da AJUP e percebido em $71 \%$ das entrevistas foi a entrada e permanência nas comunidades e nos movimentos sociais,conjuntamente com a interação entre os extensionistas da AJUP e o movimento social, que é um desafio constante, inclusive o trecho da Entrevistada 3, transcrito abaixo, ainda que se referindo à primeira geração de ajupianos pode ser repensado para qualquer momento ou geração:

[...] Bom, tiveram alguns desafios na minha opinião. Primeiro estabelecer objetivos ou metas em comum com o movimento social, e aí houve principalmente com o MTD, que era o nosso principal meio de contato com a comunidade, principalmente porque nós estávamos meio distantes, o MTD é que estava na comunidade de fato. Segundo, o de conseguir compreender nossos limites e qual seria o nosso papel como assessoria jurídica, e até que ponto se confundia a assessoria jurídica e a militância estudantil, ou 
não. É, também sentia muita falta de uma formação específica, a gente teve muita dificuldade de encontrar um coordenador que buscasse nos capacitar para que a gente de fato pudesse agregar com conhecimento jurídico (nas comunidades).[...]

Entrevistada 3

Depreende-se o que se colocou, como a inexperiência dos ajupianos no curso dificulta a compreensão dos limites da atuação da AJUP nas comunidades ou movimentos sociais e de compreensão do papel de assessoria universitária popular. Reforça como é frágil a distância do elo, ainda que necessária, entre extensão e movimento social e como é importante a atuação de um professor orientador para auxiliar e orientar quando necessário.

Quanto à atuação dos próprios estudantes extensionistas há vários desafios e dificuldades constantes, independente do período ou geração dos estudantes. A fim de demonstrar os principais eixos temáticos das dificuldades, destacou-se os trechos das entrevistas que melhor ilustram a indignação e as questões, nesse sentido:

[...] entram 20 pessoas na AJUP, sei lá, 10 ficaram, 3 faziam as coisas e se dedicavam. Os outros, ficavam esperando você falar, iam na reunião e ficavam calado [...] é complicado, porque as pessoas não encaravam a AJUP com seriedade, sabe? [...] não viam aquilo como trabalho, entende? [...]

Entrevistada 3

"[...] Ah, tem alguns desafios da AJUP também, que é o de manter pessoas comprometidas, principalmente tendo a maior parte do quadro como voluntários, com atividades que têm custos, como ir pra Pedreira. Eu acho que, eu demorei pra perceber mas eu acho que faz parte do processo, não sei, de perceber a AJUP pra além da Pedreira também, foi um processo muito importante e.... a priori os que eu posso enumerar acho que são esses mesmo.[...]

Entrevistada 4

[...] Então.. eu entrei em 2016 e eu tive bolsa em 2017. E em 2016 entrou muita gente, geralmente entra muita gente na AJUP, 2017 também entrou muita gente, só que a gente tinha um problema realmente com a participação da galera, porque esse é um tipo de problema que existe na AJUP - pelo menos nos anos em que eu estava, não posso falar dos anteriores [...] Mas essa é uma dificuldade que eu sempre encontrei na AJUP, de a galera se envolver... e em comparação com os outros projetos, o que ajuda os outros projetos.. eu acho que o problema não é nem a liberdade dos estudantes, o protagonismo estudantil, eu acho que o problema é o pouco número de bolsas que a gente tem, sabe? E muita gente também saiu da AJUP não foi porque não se identificou ou porque não queria, mas porque foi fazer estágio mesmo.[...]

Entrevistada 5

A Entrevistada 3 aponta o comodismo em delegar funções para outros instrumentos da luta movimento social ou comunidade - e a proatividade são desafios atemporais dos ajupianos. Como fazer um estudante perceber a seriedade do projeto? Como não delegar ou jogar funções que seriam da AJUP para os movimentos sociais ou comunidade? São perguntas sem respostas, pois dependem da composição humana de cada grupo e equipe que participa da AJUP.

Uma solução que tem funcionado é a coordenação das atividades, nesse contexto, é de grande valia, pois possibilita a divisão de tarefas e o acompanhamento dos anseios externos ao grupo, integrantes 
do movimento de luta - moradores e o movimento social. A proatividade e seriedade são fundamentais para o protagonismo estudantil e essencial para o desenvolvimento das atividades, assim como para a coesão do grupo.

É uma grande questão para a permanência, para o desenvolvimento da dedicação, proatividade e seriedade são as poucas bolsas disponíveis. Como há trabalho em e de campo, acompanhando e assessorando as comunidades e os movimentos sociais, há custos para os estudantes extensionistas se deslocarem e locomoverem em uma cidade cuja passagem é a mais cara do país ${ }^{6}$ ? Ou como se alimentarem, já que algumas atividades envolvem permanecer todo o dia na rua? Com o crescente arrocho econômico, a pressão familiar e de sobrevivência pessoal, é muito comum a saída de estudantes extensionistas engajados para estágios remunerados.

Sobre o momento presente, o projeto da AJUP - UFMG passa por um interregno de gerações. A diminuição do número de bolsas disponíveis - atualmente o projeto conta com 2 - e a saída de quase todos os integrantes antigos contribuiu para esse momento de estancamento e reorganização do projeto. Momento esse que contou com mais atuação da Co-coordenadora e da Orientadora a fim de direcionar os extensionistas e ensinar o que é e como funciona uma AJUP. Assim, um planejamento mais experiente é mais que necessário, dada a conjuntura atual de perseguição aos movimentos sociais.

A retomada gradativa da horizontalidade, o constante repensar das formas de agir, o desejo e necessidade de tentar conseguir outras formas de financiamento, considerando o corte de verbas agressivo das universidades públicas e das fundações de fomento à pesquisa como parte do novo projeto liberal para a periferia do sistema mundo, a retomada de leituras de pensadores fundacionais da AJUP foram escolhas tomadas no primeiro semestre de 2019 que tem gerado bons frutos, apontando que este é um caminho a se seguir.

\section{OS HORIZONTES POSSÍVEIS NA CONJUNTURA ATUAL E O PAPEL DAS AJUP}

Eduardo Galeano, em uma entrevista, conceitua utopia retomando um caso acontecido com um amigo, o diretor de cinema Fernando Birri7. Estando eles em Cartagena de Índias, os estudantes perguntaram ao diretor o que era a utopia. Ao que o diretor respondeu que a utopia está no horizonte e que nunca se alcançaria, pois à medida que uma pessoa caminha e se aproxima dela ela se afasta, pois a utopia está no horizonte. Entretanto, ainda que pareça impossível, a caminhada em busca da

6PELÁJJIO, Fhilipe.. Agora é oficial: passagem de ônibus em BH é a mais cara do Brasil; veja valores, 07/01/2019. Disponível em: <http://moonbh.com.br/agora-e-oficial-passagem-de-onibus-em-bh-e-a-mais-cara-do-brasil/>. Acesso em: 23 de agosto de 2019.

7 GALEANO, Eduardo. Para que serve a utopia? Disponível em: < https://www.youtube.com/watch?v=9iqi1oaKvzs >. Acesso em: 23 de janeiro de 2019. 
utopia nos permite apreender e melhorar várias coisas no trajeto, portanto, a utopia, na concepção deles, é esse fazer-caminhar e para alcançar melhor possível.

Ao contrário do que Eduardo Galeano e Fernando Birri nos apresentam, o dicionário Houaiss define utopia como:

[...] s.f. 1. qualquer descrição imaginativa de uma sociedade ideal, fundamentada em leis justas e em instituições político-econômicas verdadeiramente comprometidas com o bem-estar da coletividade 2. p.ext. projeto de natureza irrealizável; ideia generosa, porém impraticável; quimera, fantasia 3. FIL. POL. SOC. no marxismo, modelo abstrato e imaginário de sociedade ideal, concebido como crítica à organização social existente, porém inexequível por não estar vinculado às condições políticas e econômicas da realidade concreta. [...]. (HOUAISS, 2001)

O projeto de AJUP e a AJUP-UFMG buscam algo que muitos chamariam de utopia, assim, sendo uma mescla das definições tanto do Houaiss quanto de Galeano e Birri, a AJUP/UFMG é uma dos tantos fazer-caminhadas em busca do horizonte que se afasta à medida que nos aproximamos, daquilo que poderia ser melhor para a coletividade e o comum, ou, nas palavras de Eduardo Galeano em outro texto, do nosso direito ao delírio ${ }^{8}$ particular e da busca de uma sociedade com leis mais justas, comprometida com o bem-estar e o bem viver da e na coletividade.

Também é o momento presente, da atual geração de ajupianos, que se busca desfazer daquilo que não mais serve ou funciona e simultaneamente reconstruímos a partir do aprendizado das gerações de ajupianos, das suas experiências e das nossas experiências. Algo que ainda é muito difícil para a perspectiva linear-positivista das Universidades, a qual inclui as Universidades Públicas, mas que está dentro de culturas contra-colonizadoras de pensar: o sistema-mundo é circular e se constrói e destrói e constrói e destrói, nesse contínuo vir a ser ${ }^{9}$, que ainda é difícil de aceitar dentro da linearidade colonial que é presente nas Universidades.

E nesse caminhar, na conjuntura de perseguição aos movimentos sociais, dos ataques às universidades públicas, dos ataques às pesquisas que geram conhecimento e desse breve momento de aporia da AJUP, consideramos que é o momento de principalmente voltar para dentro e nos reestruturar. A reestruturação envolve, por exemplo, excluir alguns Grupos de Trabalho (GT), repensar algumas assessorias, planejar a volta do grupo de estudos em assessoria jurídica universitária, com pensadores tão fundamentais à AJUP e a universidade pública, tais como Paulo Freire, Roberto Lyra, Luiz Otávio Ribas e Karl Marx.

Dentro das estruturas e demandas trazidas pelos estudantes, têm-se buscado potencializar as relações horizontais internamente, ou seja, que todas ou a maioria das decisões que envolvam a

\footnotetext{
8 [...] A justiça e a liberdade, irmãs siamesas,/condenadas a viverem separadas,/voltarão a juntar-se, bem grudadinhas, ombro com ombro [...]". El derecho al delirio. Tradução livre. Disponível em: $<$ http://repositorio.uca.edu.ni/2529/1/El\%20derecho\%20al\%20delirio.pdf>. Acesso em 23 de Janeiro de 2019.

9 "Vemos de forma circular, pensamos e agimos de forma circular e, para nós, não existe fim, sempre demos um jeito de recomeçar." SANTOS, Antônio Bispo dos. Somos da terra, in PISEAGRAMA, Belo Horizonte, número 12, página 44 - $51,2018$. Disponível em: <https://piseagrama.org/somos-da-terra/>.Acesso em 23 de Agosto de 2019.
} 
coletividade e o comum da extensão. Essa reestruturação da gestão interna da AJUP reforça o protagonismo estudantil e proatividade, reduz a atuação das coordenadoras em definir todas as ações e permite que os estudantes possam se identificar mais com as decisões sobre o presente da extensão. Vale destacar que essa forma de se pensar internamente não retira a orientação e aconselhamento das coordenadoras, apenas deixa que estas formas de aconselhamento sejam para situações necessárias um seminário, uma formação, escolhas cruciais dentro dos Grupos de Trabalho ou mesmo para ensinar o protagonismo estudantil.

Atualmente, reestruturamos o processo de seleção, o qual incentivando os voluntários a já participarem da AJUP, das formações abertas e das reuniões desde o princípio e, depois de um tempo, institucionalizando-os. Percebeu-se que essa seria uma forma menos dependente do produtivismo acadêmico, mas que ainda mantenha a formalidade, por questões burocráticas da universidade e também pela dedicação dos estudantes. Inclusive, as formações abertas fazem parte desse pré primeiro momento de reestruturação da AJUP que propõe ao invés estudos fechados e exclusivos aos membros da AJUP abrirem esses minicursos às quaisquer pessoas interessadas no tema, sem a necessidade, inclusive, de se ter vínculo com a universidade.

Reconstruções que também permitem a maleabilidade da AJUP diante das conjunturas que ainda surgirão como resultado desse início de criminalização dos movimentos sociais, da destruição dos direitos sociais, das estruturas de estado de bem estar social e dos locais de construção de conhecimento. As dificuldades que inevitavelmente ocorrerão, pois os movimentos sociais que seriam assessorados podem se encontrar criminalizados e nós, ajupianos, teremos de adaptar a essa realidade e a resistência faz parte de nossas vidas, como bem lembrou a Entrevistada 2.

Como bem enfatizou Almeida, as Assessorias Jurídicas Universitárias Populares podem colaborar nesse universo dos estudantes de direito ao propor um direito crítico e tentar ir além, em busca de um direito emancipatório, pois “[...] o direito continua sendo a resposta para as questões sociais" (ALMEIDA, 2015, p.329). 0 cultivo com de vínculos com os sujeitos subalternizados também é essencial, como bem trazido nas três entrevistas.

\subsection{Conjuntura: O Brasil pós 2010}

Por que falar da conjuntura atual? Em momentos de silenciamentos, precisamos voltar ao passado para entender o presente. Olhar o passado significa relembrar os momentos de resistência que ascenderam nossa luta, enquanto movimento estudantil. 0 marco, como já dissemos, para nós no Brasil, foi a ditadura militar, o que na Faculdade de Direito da UFMG resultou na construção do espaço chamado de "Território Livre". Pensar o presente olhando através dele para analisar o passado é entender as similitudes e apreender a realidade que se aproxima. Não pretendemos aqui traçar um 
panorama histórico, nem muito menos conjecturar futurismos, mas sim descrever o momento atual de forma a possibilitar pensarmos sobre ele. Como bem afirma Almeida:

[...] para compreender os enfrentamentos da AJUP no complexo jurídico, é preciso, antes de tudo, relacionar tais enfrentamentos às condições históricas em que as forças de esquerda se encontram atualmente, hesitantes, dispersas e fragmentadas. Em última análise, as possibilidades de contribuição da AJUP com as lutas sociais dependem do contexto mais amplo em que se travam essas lutas.[...] (ALMEIDA, 2015, p. 325)

Após crescimento exponencial da economia brasileira durante o governo Lula (2003/2011) em que, com bases trabalhistas e sindicais, procurou-se uma distribuição de renda, diminuição das desigualdades norte-sul e ampliação de programas sociais, houve contínuas tentativas de golpe por parte da direita, resultando no impedimento, sem base legal, da Presidenta eleita democraticamente Dilma Rousseff em 2016. Os desmontes de direitos, tendo em conta essas questões, são descritos criticamente pelo professor Vitor Sartori:

[...] O momento presente do Brasil, ao mesmo tempo, é fruto do processo de "redemocratização" pelo qual o país passou depois da ditadura militar, e é o resultado da falência gritante deste processo. Pelo que dissemos acima, uma questão essencial para qualquer acerto de contas com um viés "antidemocrático" passa pela transformação substancial da relação entre as soluções "pelo alto", a conformação da esfera pública e o desenvolvimento econômico subordinado. Ou seja, trata-se, em verdade, de romper com as determinações que dão ensejo à "via colonial" para o capitalismo e que fazem com que o "desenvolvimento" capitalista não se ligue necessariamente à conformação "democrática" da esfera política de uma determinada formação social .[...] (SARTORI, 2017, p. 122)

O que importa para nós, a partir disso, é pensarmos os usos do direito, as fragilidades das conquistas institucionais, qual é nosso papel enquanto AJUP e, como, se isso for possível, sair da esfera em que as lutas se tornam ilusórias, uma vez que "ao mesmo tempo em que tais lutas mencionadas por Marx e por Engels não podem simplesmente ser deixadas de lado, elas conformam-se, em geral, de tal modo que se tem uma "forma ilusória de comunidade" (SARTORI, 2017, p.124).

A eleição de Jair Bolsonaro, com o vice Mourão, ambos de origem militar, apenas comprova o quão lúcidas e atuais são as reflexões do professor Vitor Sartori, nos alertando para a necessidade de rompimento com o passado militar e para as mazelas presentes derivadas de um processo de democratização que carrega características da via colonial.

A AJUP terá que se reinventar e fazer o possível para manter e dar o suporte mínimo, como bem apontou a Entrevistada 2:

[...] a gente tá num momento hoje, [...] de criminalização dos movimentos sociais né, de enxugamento da máquina pública, de retirada de direitos... direitos, inclusive, constitucionalmente estabelecidos. Então, se antes a gente reivindicava pela implementação do que tava colocado [...] Agora a gente tá falando, de cara...vamo deixar todo mundo vivo, né... muda a tônica de atuação. É um momento muito mais delicado, que exige uma atuação ainda mais incisiva da AJUP, porque tá na 
universidade, tem esse respeito da Universidade, assim... essa esse pilar da sustentação que pode ser muito... é... importante nesse momento, pra dar força pros movimentos sociais e pra organização popular assim, que vai ser extremamente atacada né, já está sendo. [...] Então, é uma assessoria que vai estar nesse contexto de acho que, aumento da violência, assim contra o povo preto pobre periférico. Então, vai ser mais difícil estar nesses lugares e prestar assessoria a essas pessoas porque essas pessoas vão estar criminalizadas, vão ser violentadas, vão estar mais ainda precarizadas. [...] Então, o papel da AJUP nessa conjuntura é de tentar dar esse suporte mínimo aí pra movimentos sociais [...] de movimentos sociais com a perspectiva de mantê-los e resistentes contra a retirada de direitos.[...]

Entrevistada 2

\subsection{Horizontes possíveis}

Frente à uma conjuntura que coloca em xeque as conquistas sociais e populares obtidas com a "redemocratização", as AJUP devem voltar os olhos para a resistência desempenhada pelas advogadas(os) populares durante a ditadura civil-militar e para as formas de organização consolidadas com o fim do regime para, então, orientarem sua práxis. Agora, mais do que nunca, faz-se necessária a criação e manutenção de fortes laços com os movimentos sociais e com as comunidades assessoradas, diante de uma perspectiva de perda de direitos e de dissolução de garantias constitucionais ${ }^{10}$. Não se deve, contudo, perder de vista as limitações inerentes ao campo jurídico.

A crítica ao direito, um dos pilares sobre os quais a AJUP se assenta, parte da compreensão marxista do direito como aporte superestrutural da sociedade civil burguesa (MARX, 2008, p.47). 0 direito, nesse sentido, é erguido por sobre a base real da economia capitalista, e reconhece, legitima e formaliza os fatos e necessidades dessa forma econômica. A igualdade jurídica, por exemplo, aparece como necessária à livre troca de mercadorias e à venda da força de trabalho (MARX, 2011, p. 219). E essa determinação de existência do Direito, como mero "reconhecimento oficial do fato" (MARX, 1985, p. 86) já objetivado (seja pela esfera econômica ou pela esfera política), é que limita a atuação dentro do campo jurídico. Acerca dessa questão, afirma Sartori:

[...] a luta política tem uma capacidade de trazer certa tensão à estruturação da própria sociedade civil-burguesa (bürgerliche Gesellschaft), no limite, ao remetendo para além da dimensão política, colocando-se como "metapolítica" (Cf. CHASIN, 1999); o mesmo, porém, não se dá diretamente com a "luta por direitos", em que, com a mediação jurídica, busca-se o reconhecimento (Anerkennung) de uma determinada conformação objetiva já conseguida anteriormente por meio das lutas sociais e políticas. (Cf. SARTORI, 2016 b). Ou seja, neste sentido específico, o Direito coloca-se a reboque da esfera política. As tensões da mesma podem perpassar a esfera jurídica quando se tem a mediação de noções que se colocam como uma espécie de "ponte" entre uma esfera e a outra, como a noção de "democracia" e de "direitos humanos", por exemplo.[..] (SARTORI, 2017, p. 112).

\footnotetext{
${ }^{10}$ Ressalta-se que permeiam por todas as entrevistas a necessidade de se buscar os direitos constitucionais que são olvidados e dificultados à algumas classes sociais. Além disso, é interessante notar, principalmente nas entrevistas 1, 3, 5, 6 e 7, como o Direito é um instrumento de manutenção de classes, mas que pode ser subvertido para, quem sabe, possibilitar alguma emancipação.
} 
Lutar pela manutenção de direitos é, de certo, resistência aos retrocessos que se apresentam diante de nós, mas o campo jurídico não pode se projetar para além disso: "O direito nunca pode ultrapassar a forma econômica e o desenvolvimento cultural, por ela determinado, da sociedade" (MARX, 2012, p 33). Tomar consciência das origens, da construção e das possibilidades de atuação da assistência jurídica universitária é, em tempos tão incertos, o primeiro passo a ser dado. E essas possibilidades de atuação jurídica só podem ser analisadas de modo crítico se houver, por parte dos membros da assessoria, uma compreensão das conformações do campo jurídico dentro da sociedade civil. Nesse sentido, temos a fala da Entrevistada 7, que aponta que "foi muito importante, logo no início ter a clareza de que dá pra usar o direito para mudar as coisas, mas não é só com o direito, o direito não basta mas tem alguma coisa que eu posso fazer a partir dele."

O horizonte exige resistência, e o tempo é de articulação e consolidação do, ainda que pequeno, potencial transformador existente nas AJUP. Segundo uma das entrevistadas sobre os horizontes possíveis ou as possibilidades de se construir algo a partir da AJUP:

[...] a missão da AJUP vai se revelando dentro das comunidades com as quais ela vai tendo contato, então eu não acho que cabe dizer "ah, sua missão é essa", e eu não sei, com quais comunidades vocês tão tendo contato agora, mas eu acho que cabe a esse contexto, a essa atuação mais local pra revelar o que que a AJUP tem que fazer no futuro, mas eu acho que... a AJUP nunca fez tanto sentido pra mim quanto agora. Principalmente porque, diferente do Pólos 11, a AJUP tem outra visão da institucionalidade, que vai ser mais desafiadora de manter mas que ao mesmo tempo dá mais liberdade - se ela conseguir se formar e se manter como equipe- de atuação, porque ela não vai depender tanto de recursos, de editais, e acaba que todas essas coisas requerem um retorno burocrático, né.[...]

Entrevistada 3

A nossa dificuldade, a ser encarada enquanto horizonte possível é a consolidação de uma base extensionista forte, a construção de uma horizontalidade entre extensionistas e coordenação, o fortalecimento do compromisso com a comunidade em que há atuação e a coesão da AJUP enquanto grupo, com membros envolvidos e responsáveis. A esse respeito, disse a Entrevistada 7:

[...] E uma outra coisa que eu acho boa também, pra manter as pessoas motivadas, tem que criar uma rede social mesmo [...] a gente chama de cultural, algo que inicialmente nos movimentos sociais é uma coisa de integração e tem um caráter mais político, pode ser um sarau, mas na nossa realidade, querendo ou não a gente vai é pro bar. A gente ia pro Banzai e era meio que quase uma chamada mesmo, "gente, essa semana tem cultural", você tinha que ir porque faz parte de ser da AJUP e ia só o pessoal da AJUP, e eu acho que esse é o clique, você tem que fazer as pessoas serem amigas, porque aí se ela faltar uma reunião ela não tá só faltando uma reunião, ela tá faltando com os amigos dela, e isso vai criar um senso de responsabilidade maior nas pessoas. E os GTs, o GT existe então ele tem que acontecer reunião toda semana. Não tem nada pra discutir? Vai acontecer reunião. Às vezes pode acontecer que não ter uma demanda muito clara, às vezes o processo tá parado, a gente não tem que ir na

11 Programa de extensão também vinculado à Faculdade de Direito e Ciências do Estado da UFMG. 
Pedreira, então a gente tem que criar coisas, fazer evento aqui na faculdade, acho que isso falta muito. [...]

Entrevistada 7

Nesse contexto, cabe também ressaltar a importância das "místicas" e da "amorosidade", apontadas por Almeida como elementos centrais à prática da assessoria jurídica popular (ALMEIDA, 2015, p.307). As "místicas", oriundas de uma íntima relação entre movimentos sociais e religiosos no contexto brasileiro, são práticas que, valendo-se tanto de elementos simbólicos quanto materiais (sejam rodas de poesia, música, teatro ou até mesmo a troca de anéis de tucum) buscam a criação de laços afetivos e de uma identidade coletiva dentro de determinado grupo. E é a "amorosidade", trazida pelas místicas, o elemento constituinte da identificação e da estruturação de um grupo que, pretendendo-se horizontal, necessita questionar a "cisão entre a vida pública e a vida privada que historicamente secundariza o lugar da subjetividade no modo de fazer política das organizações de esquerda" (ALMEIDA, 2015, p. 312).

Aliado à consolidação de uma estrutura interna do projeto, é também necessário o fortalecimento dos vínculos da AJUP com a Defensoria Pública, com outros projetos de extensão de atuação similar e com redes de advocacia popular, para que a defesa dos direitos e interesses das comunidades e dos movimentos assessorados seja ainda mais efetiva.

\section{CONSIDERAÇÕES FINAIS}

Desde sua origem a AJUP - UFMG foi combativa e teve a habilidade de se adaptar às conjunturas que se apresentavam, tais como as Manifestações de Julho de 2013, muito bem relembradas pelas entrevistas. Nessa busca de se dedicar a entender melhor o que é o grupo e como se dá a dinâmica da AJUP, se percebeu que alguns processos que achávamos exclusivos do momento presente são na verdade características constantes de todas as gerações. Essência ajupiana.

A conjuntura é a de em um momento de recessão, tanto internacional quanto nacional. Interregno. Considerando a utopia e o nosso direito de sonhar, há o desejo dos ajupianos de voltar a esse momento no qual a AJUP é protagonista e atuante. 0 recente remanejamento dos grupos de trabalho e o contato com outras demandas populares, o vínculo com novos movimentos sociais, os novos membros sinalizam os outros horizontes e os novos campos em que poderemos atuar e, com sorte e esforço, modificar para melhor a realidade que nos encontramos.

O primeiro resultado já está sendo colhido, com a abertura ao público geral das formações internas e a primeira seleção de voluntários e bolsistas, a retomada gradativa da horizontalidade com a consequente redução da atuação das coordenadoras, a leitura de textos fundacionais da AJUP e o maior envolvimento nos projetos têm sido marcante como retomada da AJUP. 
Assim, consideramos em convidar a todos a delirar nos dizeres do que Eduardo Galeano (GALEANO, 1998) chama de delírio, algo que todavia não é real tal qual a utopia, mas que combina com a capacidade camaleônica de adaptação ajupiana. Quem sabe assim não vemos melhor o que compõe uma sociedade mais justa e o que realmente devemos defender?

\author{
¿Qué tal si deliramos por un ratito? \\ ¿Qué tal si clavamos los ojos más allá de la infamia \\ para adivinar otro mundo posible? \\ El aire estará limpio de todo veneno \\ que no provenga de los miedos humanos \\ y de las humanas pasiones. [...]"12
}

Afinal, observando os pontos em comum das entrevistas, é disso que se trata ser ajupiano. Buscar modificar a realidade ao redor para quem realmente precisa, ser o agente crítico que usa o aparato jurídico de modo a impedir retrocessos e ataques às comunidades, uso contra-hegemônico e crítico. E, que com o contato próximo e horizontal com as mesmas, tenta reduzir a abissal distância existente entre o povo e as universidades. Sem, contudo, esquecer nosso passado e nossas limitações. E somente assim, partindo da compreensão crítica de nossa história e de nosso campo de atuação, é que podemos projetar nossa práxis.

\footnotetext{
12 Em tradução livre: "Que tal se delirarmos por um momentinho?/ Que tal se cravarmos o olhar para além da infâmia para adivinhar outro mundo possível?/ 0 ar estaria limpo de todo o veneno/ que não venha dos medos humanos nem das humanas paixões".
} 


\section{REFERÊNCIAS}

ALMEIDA, Ana Lia. Um Estalo nas Faculdades de Direito: perspectivas ideológicas da Assessoria Jurídica Universitária Popular. João Pessoa: Universidade Federal da Paraíba, 2015.

BRASIL. Conselho Nacional de Justiça, CNJ. 100 Maiores Litigantes 2011. Disponível em: <https://www.cnj.jus.br/images/pesquisasjudiciarias/Publicacoes/100_maiores_litigantes.p d>. Acesso em: 20/05/2019

CAPELLA, Juan-Ramón. Aprendizagem da aprendizagem: uma Introdução ao Estudo do Direito. Tradução de Miracy Barbosa de Sousa Gustin, Maria Tereza Fonseca Dias. Belo Horizonte: Fórum, 2011.

FREIRE, Paulo. Pedagogia da autonomia: saberes necessários à prática educativa. São Paulo: Paz e Terra, 1996. 24a ed, 2002.

GALEANO, Eduardo. Para que serve a utopia? Disponível em:

$<$ https://www.youtube.com/watch?v=9iqi1oaKvz s >>. Acesso em: 23 de janeiro de 2019.

Patas arriba. La escuela del

mundo al revés, Madrid, 1998, Siglo XXI, 365.

GUSTIN, Miracy Barbosa de Sousa. Das necessidades humanas aos direitos: ensaio de sociologia e filosofia do direito. Belo Horizonte: Del Rey, 1999. p. 13-37. (cap.1 e 2)

HOUAISS, ANTÔNIO. Dicionário Houaiss da Língua Portuguesa. Instituto Antônio Houaiss. 1를ição.Rio de Janeiro: Objetiva, 2001.

IBGE. INAD Contínua: 10\% da população concentravam quase metade da massa de rendimentos do país em 2017. Agência de Notícias IBGE, 11 de Abril de 2018.Disponível em: $<$ https://agenciadenoticias.ibge.gov.br/agenciasala-de-imprensa/2013-agencia-denoticias/releases/20843-pnad-continua-10-dapopulacao-concentravam-quase-metade-da- massa-de-rendimentos-do-pais-em-2017>. Acesso em 30 de Janeiro de 2019.

MARX, Karl. Contribuição à Crítica da Economia Política. Editora Expressão Popular. São Paulo, 2008.

Crítica do Programa de Gotha. São Paulo: Boitempo, 2012. 1985. Miséria da Filosofia. São Paulo: Global,

O Capital: Crítica da Economia Política.

Livro I, O processo de produção do capital. São Paulo: Boitempo, 2011.

MIGNOLO, Walter D. Colonialidade: O lado mais escuro da modernidade. In: RBCS - Revista Brasileira de Ciências Sociais. Online - vol. 32 n $^{\circ}$ 94, Trad. OLIVEIRA, Marco. 2017.

MOON BH. Agora é oficial: passagem de ônibus em BH é a mais cara do Brasil; veja valores. 07/01/2019. Disponível em: < http://moonbh.com.br/agora-e-oficial-passagemde-onibus-em-bh-e-a-mais-cara-do-brasil/>. Acesso em: 23 de agosto de 2019.

QUINTANA, A. y Montgomery, W. (org.). Psicología: Tópicos de actualidad. Lima: UNMSM, 2006. p. 58.

REAL ACADEMIA ESPAÑOLA. Diccionario de la lengua española. Disponível em:

<https://dle.rae.es/index.html> Acesso em: $10 \mathrm{de}$ janeiro de 2019.

SANTOS,, Antônio Bispo dos. Somos da terra, in PISEAGRAMA, Belo Horizonte, número 12, página 44 - 51, 2018. Disponível em: <https://piseagrama.org/somos-da-terra/>. Acesso em 23 de Agosto de 2019.

SANTOS, Boaventura de Sousa. Para uma revolução democrática de justiça. 3aed. São Paulo: Cortez, 2011.

SARTORI, Vitor Bartoletti. Direito e politicismo no Brasil: para uma análise da conjuntura nacional pré e pós golpe. In: Revice - Revista de Ciências do Estado, Belo Horizonte, v.2, n.2, p. 107-144, ago./dez. 2017. 